\title{
EFFICACY OF FUNCTIONAL ENDOSCOPIC SINUS SURGERY(FESS) IN TREATMENT OF POST NASAL DRIP (PND) AS AN ANCILLARY PROCEDURE: A COMPARATIVE STUDY
}

\author{
Saleem Asif Niazi, Shahzad Maqbool, Zafar Ullah Khan, Abdul Hakim, Muhammad Umar Aasim*, Shahid Maqsood, Yousra Riaz \\ Pak Emirates Military Hospital/National University of Medical Sciences (NUMS) Rawalpindi Pakistan, *Combined Military Hospital Bahawalpur/National \\ University of Medical Sciences (NUMS) Pakistan
}

\begin{abstract}
Objective: To assess efficacy of functional endoscopic sinus surgery (FESS) in treatment of postnasal drip (PND) as an ancillary procedure to Septoplasty with Turbinoplasty.

Study Design: Quasi experimental study.

Methodology: Sample size was n-200, Patients were placed in two groups Group A (n-126) had septoplasty with turbineplasty. Group B (n-74) included patients with Septoplasty and Turbinoplasty combined with functional endoscopic sinus surgery. Post operative results regarding postnasal drip were compared amongst the Two groups.

Results: Data was analysed in SPSS-17, Septoplasty along with turbinectomy was performed in n-126 patients (group A). And septoplasty, turbinectomy along with functional endoscopic sinus surgery was performed in n-74 patients (group B). Post nasal drip was significantly reduced in group B at 3 months follow up $(p<0.046)$. More significant difference was noted at 6 months follow up $(p<0.003)$.

Conclusion: Patients having Chronic rhinosinusitis with postnasal drip as predominant symptom, should undergo functional endoscopic sinus surgery as an ancillary procedure to conventional nasal surgery.
\end{abstract}

Keywords: Chronic rhinosinusitis, Functional endoscopic sinus surgery, Post nasal drip.

How to Cite This Article: Niazi SA, Maqbool S, Khan ZU, Hakim A, Aasim MU, Maqsood S, Riaz Y. Efficacy of Functional Endoscopic Sinus Surgery (FESS) in Treatment of Post Nasal Drip (PND) as an Ancillary Procedure: A Comparative Study. Pak Armed Forces Med J 2021; 71(Suppl-3): S573-576. doi: https://doi.org/10.51253/pafmj.v1i1.7945

This is an Open Access article distributed under the terms of the Creative Commons Attribution License (https://creativecommons.org/licenses/by-nc/4.0/), which permits unrestricted use, distribution, and reproduction in any medium, provided the original work is properly cited.

\section{INTRODUCTION}

Chronic Rhinosinusitis (CRS) is one of the most common problems that oto rhino laryngiologists have to encounter over the years on routine basis. ${ }^{1}$ The word sinusitis is applied to a group of disorders represented by inflammation (infective or allergic) of the mucosa of paranasal sinuses (PNS). The inflammation almost always involves the nose along with the PNS; hence, the term rhinosinusitis is used. ${ }^{2}$ CRS is defined as a disease that causes inflammation of Nasal and PNS mucosa with symptoms that occur for more than Twelve weeks duration. ${ }^{3}$ Major symptoms of CRS include dull facial pain/pressure, nasal obstruction, post nasal discharge (PND), hyposomia/anosmia and purulence in the nasal cavity. Minor symptoms are headache, halitosis, fatigue, dental pain, cough and ear pain. ${ }^{1}$ The pathophysiology of CRS is partial/complete blockage in drainage of secretions of PNS. The drainage of osteomeatalcomplex (OMC) can be affected by, infective process, nasal allergy, environmental and/or genetic factors. Anatomical variants of symptoms can be deviated nasal septum (DNS), hypertrophied Inferior Turbinates, Concha Bullosa, Everted uncinate process, Bulla ethmoidalis, Haller cells, Agar Nasi cells. The nasal septum,

Correspondence: Dr Saleem Asif Niazi, Associate Professor of ENT, Pak Emirates Military Hospital, Rawalpindi Pakistan despite the fact that it mainly supports structure of the nose, also plays important role in the nasal respiratory physiology. ${ }^{4}$ The location, severity, and type of DNS are the factors that influence the dynamics of airflow in the nasal cavity. Compensatory hypertrophy of the mucosa of the contra lateral nasal wall also causes complete nasal obstruction, sinus headache, sneezing, compromised olfaction and last but not the least PND. These changes in the sinonasal cavity affect the quality of life (QOL) and may lead to septum and sinus surgery. ${ }^{5}$

Septoplasty with tubinoplasty relieves the symptoms of nasal obstruction, sinus headaches, episodic sneezing and to some extent PND. But generally PND has remained a persistent symptom of post surgical patients leading to regular outpatient department follow ups and excessive medication with no results. Before the advent of FESS, patients used to be operated by conventional surgeries i.e. Septoplasty alone or in combination with turbinate surgery. These surgeries used to relieve the symptoms of nasal obstruction, episodic headaches but the problem of PND used to persist causing social problems for the patient and a sorry figure for the treating specialist. As CRS is also caused by the anatomical abnormalities of Osteo meatal complex (OMC) not addressed in conventional 
surgery. It was predicted as per studies by Thakur et $a l, 4$ that if FESS is combined with conventional surgery in our set up, the symptom of PND should improve. The objective of this one year study was to assess the efficacy of FESS in improvement of the symptom of PND as an ancillary procedure to the conventional nasal septal surgery.

\section{METHODOLOGY}

This quasi-experimental study was carried out in a tertiary care hospital in Rawalpindi. Approval by the institutional review board of this hospital, through letter No A/28/3116, was obtained. First two hundred patients, regardless of gender, reporting with CRS to ENT Out Patient Department were included in the study through sequential sampling, making a sample size of $\mathrm{n}-200$.

Inclusion Criteria: Encompassed patients with age 18-50 years; having moderate to severe DNS, with or without inferior turbinate hypertrophy and giving history of nasal obstruction, headache \& PND. Patients with CRS for more than 12 weeks; either not responding to broad spectrum antibiotics or otherwise history of poor compliance to medicine, were also included.

Exclusion Criteria: Entailed patients with Allergic rhinitis confirmed by Laboratory investigations, Vasomotor rhinitis, intra nasal polyposis. Patients with history of previous nasal surgery or having co morbid conditions like Diabetes, Hypertension, etc were also not included in the study. Our study period ranged from April 2019, to March 2020. Informed written consent was taken from all the patients. Data was collected on structured proforma endorsing demographic details ribed. Follow up visits were advised after 2 weeks, 12 weeks and 24 weeks post operatively. The patients were informed about both types of surgeries, n-126 opted for Septoplasty and turbinoplasty and n-74 opted for FESS as well, our study may have a bias here, reason for more patients opting conventional surgery may be affordability or no worry for PND. The patients were placed into two groups on the basis of surgery performed. Group-A (n-126) included patients operated by Septoplasty with Partial Inferior Turbinectomy. (PIT) or turbinoplasty. While group-B (n-74) included those who underwent septoplasty, turbinoplasty and FESS. On Follow up, PND was measured by Nose Score, as persistent, reduced and no PND. Complaints of nasal obstruction and headache were secondary variables. Data collected was endorsed in SPSS-17 for analysis. Gender, age, type of surgery were independent variables. Quantitative variables expressed as Mean \pm SD (Standard-Deviation), qualitative as percentage/ frequencies. Cross-tabulation was done via chi-square to generate $p$-value; the latter being 'less than $0.05^{\prime}$ was taken as significant.

\section{RESULTS}

Sample size was $\mathrm{n}-200$ patients. The age ranged from 18-50 years with mean age 33.8, median and mode 35years with $\mathrm{SD} \pm 9.26$. Gender distribution was males $50.5 \%$ and females $49.5 \%$. Patients in (group A) were n-126 male, female ratio. In (group B) n-74 with male to female ratio. Group B had a significant improvement in PND as compared to Group A at 3 months follow up and 06 months follow up, $p$-value being respectively $(p<0.046)$ and $(p<0.003)$ Table-I, Figure-1.

Table: Results of follow-up for pnd after 3 months and 6 months.

\begin{tabular}{|c|c|c|c|c|c|c|c|c|}
\hline \multirow[b]{2}{*}{ Groups } & \multirow[b]{2}{*}{$\begin{array}{c}\text { Total } \\
\text { No. }\end{array}$} & \multicolumn{3}{|c|}{ Follow-Up (After 3 Months) } & \multicolumn{3}{|c|}{ Follow-Up (After 6 Months) } & \multirow{2}{*}{$\begin{array}{c}p \text {-value } \\
\text { after } 6 \\
\text { months }\end{array}$} \\
\hline & & No PND & $\begin{array}{l}\text { Reduced } \\
\text { PND }\end{array}$ & $\begin{array}{l}\text { Persistent } \\
\text { PND }\end{array}$ & No PND & $\begin{array}{c}\text { Reduced } \\
\text { PND }\end{array}$ & $\begin{array}{l}\text { Persistent } \\
\text { PND }\end{array}$ & \\
\hline Group A & 126 & 23 & 68 & 35 & 36 & 49 & 41 & 0.046 \\
\hline Group B & 74 & 24 & 37 & 13 & 36 & 28 & 10 & 0.003 \\
\hline
\end{tabular}

along with type and outcomes of surgery. All the patients were admitted a day prior to surgery preceded by clinical work-up through ENT \& endoscopic examination; relevant investigations like CT scan of nose \& PNS without contrast were done. The patients underwent elective surgery the next day by ENT consultant under general anesthesia. All were placed, postoperatively, on broad spectrum I/V antibiotic cover for 48 hours and later in continuation on oral antibiotics for further 5 days. Nasal decongestants, intranasal saline douches, antihistamines and NSAIDs were also presc-
Regarding complaints of nasal obstruction in group A 106 patients had marked improvement and n-20 patients had partial improvement, in group B n-64 had marked improvement and n-20 had partial improvement, (Figure-II). As far as headaches were concerned in group A n-68 got relief, n-39 had partial relief and n19 had no improvement, in group B, headache was relieved in n-48, partial improvement was noted in n22 and no improvement was observed in n-4 patients, (Figure-III). This data was analyzed and was statistically not significant. 


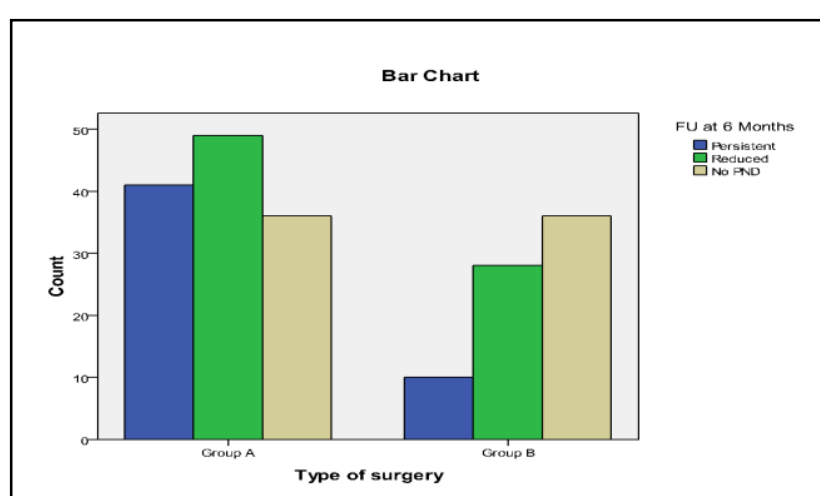

Figure-1: Type of surgery and effect on pnd 06 months follow up.

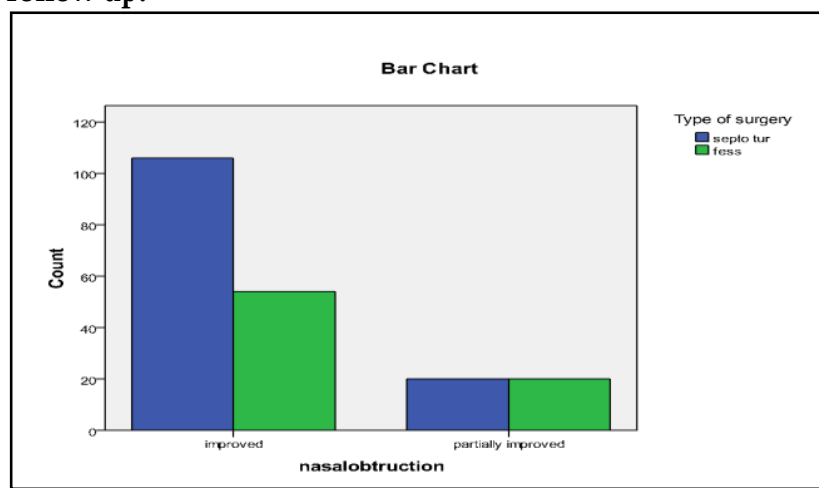

Figure-2: Comparison of group a and group $b$ type of surgery on nasal obstruction.

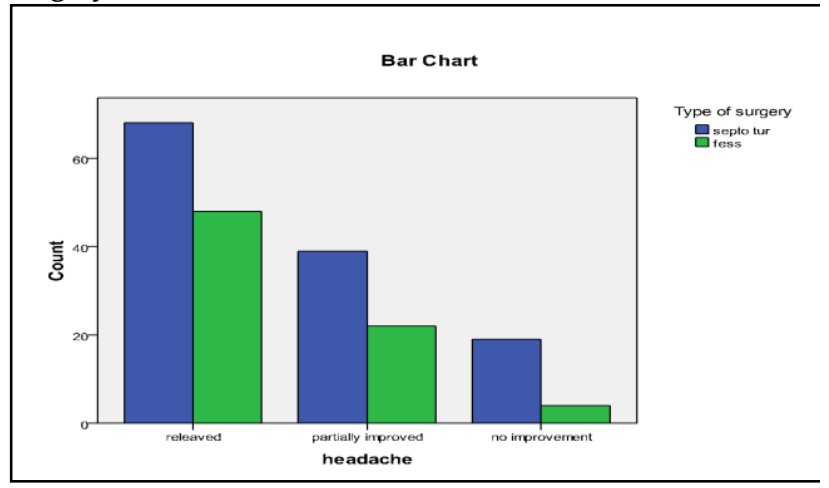

Figure-3: Post op effect of group a and group b surgery on headache.

\section{DISCUSSION}

In our study, group A was subjected to Septoplasty \& partial turbinoplasty. In this group only $28.57 \%$ of the patients had improvement in PND. Rachna Singh et al, conducted a similar small scale study (n50), and concluded that septoplasty with turbinectomy alone does not significantly improve the symptoms of CRS and recommended that FESS should be concomitantly combined with it. ${ }^{1}$ FESS is one of the most common surgical procedure performed these days for chronic sinus diseases. ${ }^{6}$ Patients in group B were subjected to FESS, in addition to the conventional septoplasty and turbinate surgery, with the aim of removal of the diseased tissue causing obstruction of Osteo meatal complex \& restoring normal sinonasal ventilation. FESS was performed by the standard surgical technique, practiced worldwide. Uncinectomy, was the first step, to expose middle meatus after its medialisation. Middle meatal antrostomy was done and diseased mucosa cleared. The maxillary antrum was flushed with normal saline, the Ethmoidal, frontal and sphenoidal sinuses were only addressed depending upon the extent of involvement on CT Scan and assessment by the surgeon. This group had a significant $(48.65 \%)$, improvement in PND.

In our study, improvement in PND was measured using Nose score 7 and documented at 03 months $(p<$ $0.046) \&$ then at 6 months $(p<0.003)$ of follow up; which was statistically significant. A similar study supporting our result was conducted by Dr Chattopadhyay in which there was significant improvement in PND after FESS with a $p$-value of 0.01 .2 Other symptoms like nasal obstruction, headache had compatible outcomes in both the groups.

CRS is a common disease encountered in daily ENT practice. Diagnosis of chronic and recurrent sinusitis can be made clinically upon history and examination, by finding pus in the meatus, nasal cavity or throat, either anteriorly or posteriorly. Radiographs should be obtained to confirm the diagnosis which, often, illustrate an opaque sinus and thickened mucous membrane. But since the advent of FESS, coronal CT scan of PNS with or without contrast, has become investigation of choice as it helps the endoscopic surgeon view to the sino nasal cavity. ${ }^{8}$ Reported prevalence rate of CRS, ranges from $1-12 \%$ worldwide. ${ }^{9}$ It affects both genders equivocally. It involves an increasing proportion of the adult population until the sixth decade, declining thereafter. ${ }^{1}$ Likewise, mean age of our patients was 33.8 with a standard deviation of \pm 9.625 .

By definition it is a chronic inflammatory disease of the PNS lasting $>12$ weeks affecting two or more major sinuses; with or without findings on physical examination. ${ }^{1}$ Anatomical variations and mucosal hypertrophy of the nose \& PNS lead to the symptoms of CRS. The maxillary sinus is the commonest to be affected due to DNS obstructing OMC. ${ }^{10}$ Common symptoms include dull facial pain/pressure, nasal obstruction, rhinorrhea or post nasal discharge, hyposmia /anosmia, purulence in the nasal cavity on examination. ${ }^{11}$ Nasal discharge/PND remains a major presenting symptom in CRS. ${ }^{2}$ Rudmik et al, owing to the 
chronic nature of the condition, warranted long-term conservative control by medications or surgery for successful outcomes, ${ }^{12}$ Medical and especially local treatment is the first line of treatment for the relief of CRS symptoms. Surgical treatment is indicated and performed on patients noncompliant to medication and conservative topical treatment. ${ }^{13}$ In our study all the patients were first subjected to conservative treatment for consecutive 3 weeks, and only inducted in the study if their symptoms persisted, reoccurred or showed no improvement by twelve weeks. CT scan remains the standard diagnostic tool for CRS, by delineating the extent of disease, and also elaborating anatomy of OMC for FESS. Septoplasty i.e. surgical correction of the deviated nasal septum, is the most common ENTsurgical procedure in adults. The main indication for septoplasty is nasal obstruction. Septoplasty (with or without turbinate surgery) is performed to widen nasal passages and thus improve nasal airflow. ${ }^{14}$

FESS remains the most effective treatment option for the surgical treatment of CRS. Huang et al, conducted a study, in USA, and concluded that FESS had a success rate of $98 \%$ in effectively treating CRS. ${ }^{15}$ A similar study in Japan concluded that FESS is safe and standard treatment in management of CRS refractory to non surgical treatment. ${ }^{16} \mathrm{Com}$-bining conventional nasal surgery with modern endo-scopic approaches rendered better results as shown by Chaitanya et al. ${ }^{17}$ They observed that when FESS was performed without correcting the anatomical abnorma-lities like DNS, there was $20.62 \%$ incidence of residual or recurrent disease. They further added, when pre and postoperative quality of life improvement was tabulated using SNOT 22 symptoms, there was more improvement when septoplasty was performed along with FESS. However, ENT surgeons like Goel et al ${ }^{8}$ \& Bayiz et al. ${ }^{18}$ Conducted studies which strongly opine that septoplasty alone can be adequate in treating CRS with DNS.

\section{LIMITATION OF STUDY}

Surgery included smaller sample size, a large scale meta analysis would further prove the role of FESS in improving the PND. Uneven distribution of patients in the two groups is another bias, this was because of patient not opting for an additional surgery. The study is one of its kind in the country and would help other researchers to take it further.

\section{CONCLUSION}

Patients with CRS having PND secondary to DNS, as dominant symptom should undergo FESS as ancillary procedure to Septoplasty and turbinoplasty.

\section{Conflict of Interest: None.}

\section{Authors' Contribution}

SAN: Conceptualization of study design, drafting and revision, SM: Literature search, data acquisition, write up, ZUK: Data interpretation, write up, AH: Literature search, data collection and analysis, MUA: Data analysis, write up, SM: Data acquisition and analysis, YR: Literature search, data analysis.

\section{REFERENCES}

1. Singh R, Rana AK, Narula SS. Is only septoplasty justified in deviated nasal septum with chronic rhinosinusitis? J Clin Diag Res 2019; 13(1): $1-4$.

2. Chattopadhyay PK. Analysis of Ocome of FESS performed in Patients-J Advan Med Dental Sci Res 2019; 7(2): 78-80.

3. Imran S, Nursiah S, Sofyan F, Ashar T. The role of functional endoscopic sinus surgery (FESS) to improve olfactory function in chronic rhinosinusitis patients without polyps. Bali Med J 2017; 6(3): 641-644.

4. Thakur K, Gupta VD, Surya M, Ahluwalia A. Comparative evaluation of FESS and septoplasty with FESS in cases of DNS with chronic maxillary sinusitis. Inter J Res Med Sci 2017; 5(8): 3523-3529.

5. Berkiten G, Kumral TL, Salturk Z, Atar Y, Yildirim G, Uyar Y, et al. Effect of deviated nasal septum type on nasal mucociliary clearance, olfactory function, quality of life, and efficiency of nasal surgery. J Craniofac Surg 2016; 27(5): 1151-1155.

6. Shah SJH, Ali M. Comparison of efficacy of FESS (functional endoscopic sinus surgery) versus conventional intranasal polypectomy in patients with nasal polyposis. J Raw Med Coll 2018; 22(3): 227-230.

7. Shukla RH, Nemade SV, Shinde KJ. Compression of visual analogue scale (VAS) and the nasal evaluation (NOSE) score in evaluation of post septoplasty patients. World J Otorhinolaryn-gol-Head Neck Surg 2020; 6(1): 53-58.

8. Aggarwal S, Sharma DK, Kaur R, Ramdev B, Rishi P, Sharma SR. Comparative evaluation of septoplasty versus septoplasty with functional endoscopic sinus surgery (FESS) in 50 cases of chronic maxillary sinusitis. Inter J Res Rev 2020; 7(2): 279-286.

9. Xu Y, Quan H, Faris P, Garies S, Liu M, Bird C, et al. Prevalence and incidence of diagnosed chronic rhinosusitis in Alberta, Canda. JAMA Otolaryngol Head Neck Surg 2016; 142(11): 1063-1069.

10. Goel AK, Yadav SPS, Ranga R, Gulia JS, Goel R. Comparative study of septoplasty alone and with FESS in maxillary sinusitis with septal deviation. Clin Rhinol An Inter J 2012; 5(1): 19-24.

11. Halawi AM, Smith SS, Chandra RK. Chronic rhinosinusitis: epidemiology and cost. Aller Asthma Proceed 2013; 34(4): 328-334.

12. Rudmik L, Soler ZM. Medical therapies for adult chronic sinusi-tis: a systematic review. JAMA 2015; 314(9): 926-939.

13. Tsuzuki K, Hashimoto K, Okazaki K, Sakagami M. Post-opera-tive course prediction during endoscopic sinus surgery in pati-ents with chronic rhinosinusitis. J Laryngol Otol 2018; 132(5): 408-417.

14. Van Egmond M, Rovers MM, Tillema AHJ, van Neerbeek N. Septoplasty for nasal obstruction due to a deviated nasal septum in adults: a systematic review. Rhinol 2018; 56(3): 195-208.

15. Huang BY, Lloyd KM, DelGaudio JM, Jablonowski E, Hudgins PA. Failed Endoscopic Sinus Surgery: Spectrum of CT Findings in the Frontal Recess. Radio Grap 2009; 29(1): 177-95.

16. Suzuki S, Yasunaga H, Matsui H, Fushimi K, Kondo K. Complication rates after functional endoscopic sinus surgery: analysis of 50,734 Japanese patients. The laryngoscope 2015; 125(8): 1785-1791.

17. Chaitanya KV, Janardhan N, Rakesh G, Michael G, Sumanth KK Role of septoplasty with endoscopic sinus surgery in management of patients of chronic rhino sinusitis? a prospective randomized observational study. Schol J Appl Med Sci 2015; 3(1G): 508-513.

18. Bayiz U, Dursun E, Islam A. Is septoplasty alone adequate for the treatment of chronic rhinosinusitis with septal deviation?. Am J Rhinol 2005; 19(6): 612-616. 